\title{
Bruxismo em Crianças
}

\author{
NOR, Jacques Eduardo* \\ FELDENS, Eliane Gerson* \\ WITT, Sandra Maria Rigatto* \\ SCHERER, Suzane Cristina* \\ THOMAZI, Thomaz Horn* \\ MARTINS, Eleutério Araújo** \\ NUNES, Rejane ${ }^{\star \star *}$ \\ ARAÚJO, Fernando Borba $* * * *$
}

\section{RESUMO}

O presente trabalho se destinou a revisar a literatura pertinente aos ítens principais a respeito de:

1. Conceitos de bruxismo

2. Levantamentos epidemiológicos em crianças

3. Etiologia

4. Sinais e sintomas dos distúrbios funcionais de ATM e Músculos Mastigatórios

5. Exame e diagnóstico

5.1. Anamnese

5.2. Clínico

6. Das desordens de disfunção de ATM e músculos mastigatórios nas crianças.

\section{SUMMARY}

This paper presents the literature review of the folowing items:

- Bruxism concept

- Epidemiology of Bruxism in Children

- Etiology

- Signs and sintoms of the TMJ

- Examination of pacients with. Problems in TMJ.

\section{DESCRITORES}

\section{ABRASĀO DENTÁRIA • BRIQUISMO • SÍNDROME DA ARTICULAÇĀO TEMPOROMANDIBULAR DENTIÇĀO DECÍDUA}

\section{INTRODUÇÃO}

Atualmente é notória a grande preocupaçāo direcionada às disfunçōes do Sistema Estomatognático. Muito se tem pesquisado a respeito da etiologia, diagnóstico e tratamento das alteraçōes dentárias, musculares, neurológicas e articulares envolvidas na manifestaçăo do bruxismo em adultos.

$\mathrm{Em}$ odontopediatria, entretanto, as constantes modificaçöes decorrentes do desenvolvimento e crescimento dos arcos dentários e seu relacionamento, tornam particularmente complexos 0 diagnóstico e planificaçāo de tratamento destas entidades clínicas.

Além disto, torna-se necessária uma visāo preventiva, ou seja, um estudo e trabalho direcionados para a abordagem precoce de problemas cuja postergaçāo no diagnóstico poderá resultar em dificuldades futuras para sua resolução.

A proposta deste trabalho é abordar aspectos relativos à etiologia, diagnóstico e características da manifestação do bruxismo em crianças.

\section{CONCEITOS DE BRUXISMO}

Marie \& Pietkiewiez 23 (1907), introduziram o termo "Bruxomania" para designar o hábito de cerramento de dentes, o qual seria causado pelo aparecimento de lesōes corticais dolorosas e, ocasionalmente, por distúrbios na medula óssea.

Frohman 13 (1931), foi o primeiro autor a utilizar o termo BRUXISMO. Além desta, outras denominaçōes foram utilizadas para designar esta disfunçäo, como por exemplo: "Nevralgia traumática" por Karolyl 19 (1906), "Neurose do hábito oclusal" por Tishler 34 (1928) ou "Parafunção" por Drum 9 (1956).

Atualmente o bruxismo é descrito como o fenômeno que consiste no hábito de triturar, ranger ou apertar os dentes repetida ou continuamente, durante o dia ou a noite, em atividades não funcionais - Ramfjord \& Ash 28 (1972).

\footnotetext{
* Alunos do curso de pós-graduação em Odontopediatria, nível de especializaçāo da F.O./UFRGS

** Professor titular da disciplina de oclusäo da F.O./UFRGS

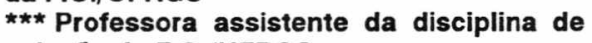
oclusäo da F.O./UFRGS

$\star \star \star \star$ Professor adjunto da disciplina de odontopediatria da F.O./UFRGS
} 


\section{LEVANTAMENTOS EPIDEMIOLÓGICOS EM CRIANÇAS}

Grosfeld (14), encontrou que $56,4 \%$ das crianças de 6 - 9 anos e 67,6\% na faixa etária de 13 - 15 anos apresenta sinais e/ou sintomas de bruxismo.

Segundo Lindqvist (21), 47\% das crianças apresenta facetas atípicas de desgaste dental. Já Maria Nilner (25), em estudo realizado em 1977, encontrou $77 \%$ de prevalência de bruxismo em crianças com idade variando entre 7 e 14 anos, e de $74 \%$ entre 15 e 18 anos.

Utilizando uma faixa etária mais abrangente, 6 - 16 anos, Ingerslev (17) encontrou um percentual de $42 \%$ de presença de sinais e sintomas de bruxismo.

Bungaard-Forgensen (6) afirmou em 1960, que o bruxismo está presente em algum momento na vida de todas as crianças.

\section{ETIOLOGIA DO BRUXISMO}

O bruxismo tem sido classificado segundo sua etiologia provável em:

1. Origem Local

- Maloclusảo

- Interferência Oclusal

- Padrăo de Erupção alterado em Decíduos e/ou Permanentes

- Dentes Perdidos

- Cistos Dentígeros

- Presença de Cálculo Dental

- Reabsorção Radicular

2. Origem Sistêmica

- Padrāo Alérgico

- Distúrbios de Otorrinolaringologia

- Deficiências Nutricionais e/ou Vitamínicas

- Imbalanços Enzimáticos

- Distúrbios Gastro-intestinais

- Desordens do Sistema Endócrino (Hipertireoidismo)

- Influências de Ordem Genética

- Hipercinese

\section{Origem Psicológica}

- Estados de Ansiedade e Depressāo

- Situaçōes de Stress Emocional

- Expressão do Medo ou Hostilidade

- Crianças em Fase de Auto-afirmaçăo

- Crianças em Fase de Descoberta de Expressão pelo Vocabulário

4. Origem Ocupacional

- Crianças que Participam de Atividades Esportivas

- Crianças que são cobradas em demasia nas atividades escolares

- Crianças que atuam em atividades meticulosas e precisas

\section{Origem ligada à Padrāo de}

Desenvolvimento

- Tentativa de criar um plano individual, a fim de obter uma situaçāo de repouso muscular, trazendo como consequência a instalação de bruxismo anterior (Dentiçāo Decídua)

Dentre os prováveis fatores causais do bruxismo citados anteriormente, convém ressaltar:

Interferências Oclusais - A correlaçāo da presença de contatos nāo-funcionais entre as peças dentárias e a incidência de bruxismo foi feita por vários autores. Lindqvist (20) encontrou que $55 \%$ das crianças que apresentavam bruxismo eram portadoras de interferências oclusais em estudo feito em 1973. Já Ingervall (18), encontrou esta correlaçāo em $80 \%$ das crianças por ele examinadas.

Maloclusão - Vários autores como Egermark-Eriksson (12), Solberg (32), Ingervall (18) e Carlsson (7) comprovaram existir um aumento na prevalência de bruxismo quando feito estudo em pacientes portadores de maloclusōes como mordida cruzada anterior e/ou posterior, sobremordida, mordida aberta anterior, giroversão, degrau mesial ou distal para a mandíbula.

Padrão Alérgico - Marks (22), em 1980, diz que o bruxismo pode ser iniciado por uma situação de pressāo negativa no ouvido médio e/ou interno causada por edema de fundo alérgico na Trompa de Eustáquio. O seu estudo demonstrou haver uma ocorrência três vezes maior do bruxismo em pacientes alérgicos, quando comparados aos pacientes normais. O período crítico, segundo o autor, abrange a fase compreendida entre o nascimento e os 7 anos de idade.

Distúrbios Otorrinolaringológicos Arlen (3), em 1983, e Thornburn (33), em 1985, demonstraram que a inter-relação embriológica, anatômica e neurológica existente entre as estruturas do Sistema Estomatognático e o ouvido justifica a incidência de patologias envolvendo estes orgāos em conjunto.

Origem Psicológica - A estimulação dos componentes do Sistema Límbico como o hipotálamo, lobo límbico, hipocampo e núcleos amigdalóides, pode ser resultado de estados de tensão emocional. Sabe-se, atualmente, que uma das funçōes destes órgāos é a modulaçāo no trânsito de mensagens entre o córtex cerebral $\theta$ as estruturas do Sistema Estomatognático. Deste conhecimento, pode-se concluir que a situaçāo emocional da criança pode torná-la mais ou menos predisposta a desenvolver um padrāo de bruxismo. Esta correlaçāo foi descrita por Scharer (30), em 1974.

\section{SINAIS E SINTOMAS DOS DISTÚRBIOS FUNCIONAIS DE ATM E MÚSCULOS}

- Episódios dolorosos frequentes

- Restrição de movimentaçāo mandibular

- Desvio da mandíbula para o lado comprometido

- Ruídos articulares

- Sensibilidade à palpaçăo (ATM e Músculos Mastigatórios)

- Edema

- Zumbido, vertigem e surdez.

\section{EXAME E DIAGNÓSTICO}

O estabelecimento de um diagnóstico preciso das alteraçōes do Sistema Estomatognático torna-se possível através de um conhecimento prévio das características da manifestação deste grupo de patologias na criança. Além disto, a orientação de um roteiro para exame, completo e direcionado, é imprescindível para a obtenção dos dados necessários para a avaliação global do paciente.

Torna-se importante entāo, a proposiçāo de uma alternativa para a ordenação de atitudes e recursos disponíveis para o exame do paciente, uma vez que o bruxismo está inserido numa entidade complexa chamada Síndrome de Dor e Disfunção do Sistema Estomatognático, que apresenta uma enorme gama de sinais, sintomas e interaçōes que podem dificultar sobremaneira o estabelecimento de um diagnóstico preciso.

\section{Anamnese}

Com crianças, torna-se muito importante a realizaçāo da anamnese em lugar tranquilo, para que esta sinta-se bem a vontade para responder às nossas indagaçōes. A participaçāo dos pais é fundamental, uma vez que somente estes terão condiçōes de nos informar a respeito da história médica geral, remota e atual, da criança, bem como nos dar informaçōes precisas à respeito de dados como: ranger noturno de dentes, tiques nervosos, hábitos de mordida, hábitos viciosos, queixas de sintomatologia dolorosa e relação familiar e social.

Por fim, é importante que, neste momento, seja feita uma avaliação do perfil psicológico da criança, uma vez que sabe-se, atualmente, que o estado emocional pode modular a açāo das estruturas do Sistema Estomatognático e influenciar no desencadeamento do bruxismo.

\section{Exame Clínico}

2.1 - Observação - Devemos observar o paciente desde o primeiro contato, avaliando seu caminhar, sua postura, presença de assimetrias ou de edema facial, hábitos viciosos de deglutição e características da sua respiração. A obser- 
vação das māos do paciente podem nos informar a respeito de alteraçōes emocionais e presença de artrites.

2.2 - Palpação - Um dos sintomas importantes a serem diagnosticados é a presença de dor ou alteraçōes nos músculos mastigatórios e ATM. A palpaçāo poderá nos informar a respeito de nódulos, áreas hipertônicas, áreas espásticas e pontos-gatilho.

A musculatura a ser examinada compreende todos os músculos mastigatórios, supra-hioideos, cervicais e da cabeça.

2.3 - Auscultação - da oclusảo dentária, pode revelar a ocorrência de prematuridades;

- Da ATM, pode revelar:

a. click - que é sinal de alteraçōes na inter-relaçāo do complexo disco-côndilo ou na funçāo dos músculos pterigoídeos-laterais, nos seus ventres superior e/ou inferior.

b. crepitaçăo - indicativo de degeneraçōes intra-articulares.

2.4 - Movimentação Mandibular - Deve-se observar e mensurar os movimentos de abertura, fechamento, lateralidade, protrusāo e retrusāo. A presença de desvios ou de limitação nos diferentes movimentos revelam acomodaçōes, funcionamento neuro-muscular assimétrico ou anomalias de ATM.

2.5 - Tecidos Moles - Sua avaliaçāo pode revelar a presença de atividades para-funcionais. $O$ exame destas estruturas deve ser feito através de inspeçāo visual e táctil e pode demonstrar a presença de marcas de mordidas, ulceraçōes ou sul- cos e marcas de apertamento nas bochechas e nos lábios.

2.6 - Língua - Alteraçōes nas suas funçōes sensoriais e motoras determinam modificaçōes no padrāo mastigatório do paciente. As alteraçōes na sua forma, como a presença de marcas dos dentes nos seus bordos laterais, podem nos auxiliar no diagnóstico de um bruxismo cêntrico.

2.7 - Análise Oclusal Imediata - Deve ser feita através de dois tipos de avaliaçāo:

a. Avaliação Morfológica

Deve-se considerar:

- ausências dentárias, migraçōes e extrusōes

- cunvas de Spee e de Wilson

- sobrepasses horizontal e vertical

- presença de facetas de desgaste (localizaçāo e severidade)

- fraturas de coroa, restauraçōes e raízes

- maloclusōes

b. Avaliaçāo Funcional

Durante a movimentaçảo da mandíbula, deve-se observar:

- deslizamento entre relação cêntrica e posiçāo intercuspal

- interferências no lado de balanceio e lateralidade.

É necessária uma avaliação detalhada das facetas de desgaste, a fim de:

- diferenciar as facetas normais das atípicas

- diferenciar as facetas polidas (deslizamento), das rugosas (apertamento)

É importante ressaltar a grande incidência de desgastes encontrada nos cani- nos, sendo um dos grupos dentais mais envolvidos tanto na dentiçăo decídua quanto na permanente.

2.8 - Análise Oclusal Mediata - Quando indicada, deve ser feita através da montagem de modelos no articulador, à partir de posiçăo de relaçäo cêntrica, visando a avaliaçāo de detalhes nāo perceptíveis na análise imediata.

$\mathrm{O}$ uso de articuladores permite:

- detecção de prematuridades

- detecção de interferências nas diferentes posiçōes

- mapeamento

2.9 - Avaliação da Função Neuromuscular - Deve ser feita através da observaçāo clínica de posição postural e movimentaçāo orientada da mandíbula.

Observa-se:

- inclinaçōes permanentes da cabeça

- tremores em movimentação além da posiçāo intercuspal

- movimentos não conscientes (cacoetes), o que pode demonstrar implicaçōes do nervo facial ( $7^{\circ} \mathrm{par}$ )

- capacidade de realizar movimentos lentos e suaves

- movimentação de olhos e membros

- facilidade para deslizamentos em lateralidade, o que pode demonstrar implicaçōes dos músculos Masseter, Temporal e Pteriogoídeo-externo.

2.10 - Exames Radiográficos - Estāo indicados somente quando existem suspeitas de alteraçōes degenerativas, estruturais ou neoplásticas, que à critério do clínico, já possam ser apreciadas em exposiçōes radiográficas. 


\section{REFERÊNCIAS BIBLIOGRÁFICAS}

1. AHMAD, R. Bruxism in children. J. Pedod., v. 10, n. 2, p. 105-126, 1986.

2. ARGERBERG, G.; WANMAN, A. Mandibular dysfunction in adolescents. Acta Odontol. Scand., v. 44, p. 47-61, 1986.

3. ARLEN, H. Otolaryngologie manifestations of cranio-mandibular disorders. Symposium on temporomandibular dysfunction and treatment. Dent. Clin. North Am., v. 27, n. 3, p. 523-526, 1983.

4. ARLEN, H. The Otomandibular syndrome: a new concept. Ear Nose Throat J., v. 56, p. 61-64, 1977.

5. ARLEN, H. The otomandibular syndrome: diagnosis. Ear Nose Throat J., v. 60, p. 50-53, 1978.

6. BUNGAARD - JORGENSEN, F. Afslapningsovelser som led $\mathrm{i}$ behandlingend af habituelle dysfunktioner i mastikationsapparatet. Odont. T., v. 58, p. 448-454, 1950.

7. CARLSSON, G.E., et al. Frequence of symptons of mandibular dysfunction in young swedish men. J. Oral Rehabil., v. 3, p. 9-18, 1976.

8. DAWSON, P. Avaliaçāo, diagnóstico e tratamento dos problemas oclusais. Sāo Paulo: Artes Médicas, 1980. 405 p.

9. DRUM, W. Klassification von parafunktionen. Dtsch. Zahnartzl., v. 17, p. 411, 1962.

10. EGERMARK-ERIKSSON, I. Malocclusion and some functional recordings of the mastigatory system in swedish schoolchildren. Swed. Dent. J., v. 6, n. 1, p. 9-20, 1982.

11. EGERMARK-ERIKSSON, I. \& INGERVALL, B. Anomalies of occlusion predisposing to occlusal interference in children. Angle Or- thod., v. 52, n. 4, p. 293-299, oct., 1982.

12. EGERMARK-ERIKSSON, I., et al. The Dependence of mandibular dysfunction in children on functional and morphologic malocclusion. Am. J. Orthod., v. 83, n. 3, p. 187-94, mar., 1983.

13. FROHMAN, B.S. The Application of psichotherapy to dental problems. Dent. Cosmos. v. 73, p. 1117, nov., 1931.

14. GROSFELD, O.; CZARNECKA, B. Musculo-articular disorders of the stomatognathic system in school children examined according to clinical criteria. J. Oral. Rehabil., v. 4, p. 193-200, 1977.

15. HOLM, A.K. Oral health in 5 years old swedish children. Community Dent. Oral Epidemiol., v. 3, p. 184-187, 1975.

16. HELSING, L.D.S. et al. Temporomandibular joint disorders: a diagnostic challenge. J. Prosthet. Dent., v. 56, n. 5, p. 600-605, nov., 1986.

17. INGERSLEV, H. Functional disturbances of the mastigatory system in school children. J. Dent. Child., v. 50, n. 9, p. $445-449$, nov/dec., 1983.

18. INGERVALL, B. Tooth contacts on the functional and non-functional side in children and young adults. Arch. Oral Biol., v. 17, p. 191-200, 1972.

19. KAROLYL, M. Zur Therapie der erkrankankungen der mundshleimhaut. Viertteljschr. Zahnhk., v. 22, p. 226, 1906.

20. LINDQVIST, B. Occlusal interference in children with bruxism. Odontol. Revy, v. 24, p. 141-148, 1973.

21. LINDQVIST, B. Bruxism in children. Odontol. Revy, v. 22, p. 413-424, 1971.

22. MARKS, M.B. Bruxism in allergic children.
Am. J. Orthod., v. 77, n. 1, p. 48-59, 1980.

23. MARIE, M.M.; PIETWIEKWICZ, M. La bruxomanie. Rev. Stomat., v. 14, p. 107, 1907.

24. NADLER, S.C. Bruxism, a classification: critical review. J. Am. Dent. Assoc., v. 54, p. 615-622, 1957.

25. NILNER, M. Prevalence of functional disturbances and diseases of the stomatognathic system in children aged 7-14 years. Swed. Dent. J., v. 5, p. 173-187, 1981.

26. NILNER, M. Relationships between oral parafunctions and functional disturbances and diseases of the stomatognathic system among children aged $7-14$ years. Acta Odontol. Scand., v. 41, p. 167-72, 1983.

27. NUNES, R.; MARTINS, E.A. Sistema Estomatognático: exame, Porto Alegre: 1987.

28. RAMFJORD, S.; ASH, M.M. Oclusāo. 3. ed., Rio de Janeiro: Guanabara, 1987. 422 p.

29. RIEDER, C. The prevalence of mandibular dysfunction. Part 1 : sex and age distribuction of related signs and symptons. J. Prosthet. Dent., v. 50, n. 1, p. 81-87, july, 1983.

30. SCHARER, P. Bruxism. Front. Oral Phsiol., v. 1, p. 293-322, 1974.

31. SOLBERG, W.K. et al. Prevalence of mandibular dysfunction in young adults. J. Am. Dent. Assoc., v. 98, p. 25-34, jan., 1979.

32. SOLBERG, W.K. et al. Temporomandibular joint pain and dysfunction: a clinical study of emotional and occlusal components. J. Prosthet. Dent., v. 28, n. 4, p. 412-422, 1972.

33. THORNBURN, D.N.; BLAKE, P. Mandibular dysfunction in children with otalgia. N. Z. Dent. J., v. 81, p. 89-92, july, 1985.

34. TISHLER, B. Occlusal habit neurosis. Dent. Cosmos, v. 70, p. 690, july, 1928. 